Revista Eletrônica do Mestrado em Educação Ambiental

Programa de Pós-Graduação em Educação Ambienta1

\title{
Muros y educación, dos tristes inecuaciones de la educación en Pereira, Colombia $^{1}$
}

Miguel Alberto González González ${ }^{2}$ Universidad de Manizales (Colombia) http://orcid.org/0000-0002-0172-0101

Alexander Wchima Monsalve ${ }^{3}$ Universidad de Manizales (Colombia) https://orcid.org/0000-0001-5813-5571

Resumen: Este artículo de reflexión, proveniente de la investigación adelantada para la tesis doctoral (2016-2020), titulada, Espacios confinados. Muros físicos y simbólicos en la ciudad de Pereira, Colombia: una pregunta por la educación, parte de una discusión sobre la ideología de la seguridad, como perspectiva clasista y autoritaria que desconoce los derechos de la gran mayoría de la población, bajo el pretexto de un agresor externo. Entre los derechos conculcados por esa ideología, se encuentra la educación, y levanta muros en la escuela para proteger a los estudiantes de un diálogo directo con el mundo. Frente a este escenario de espacios confinados, y a manera de conclusión, se propone, en primera instancia, la supresión, el derrumbamiento de los muros físicos existentes para abrirse a la comunidad, para oponerse al amurallamiento de las realidades, en segundo momento, gestar una pedagogía crítica que facilite un encuentro dialógico entre los actores de la comunidad educativa, los saberes y prácticas que allí se concitan para contrarrestar el pensamiento a favor de los muros.

Palabras clave: Muros en la educación, ideología de la seguridad, segregación espacial, educación confinada, pensamiento de frontera.

\footnotetext{
${ }^{1}$ Este artículo proviene de la investigación para optar al título de doctor en Formación en Diversidad, en la Universidad de Manizales (Colombia).

${ }^{2} \mathrm{PhD}$ en Ciencias de la Educación de la Universidad Tecnológica de Pereira (Colombia) y PhD en Conocimiento y Cultura para América Latina. IPECAL (México). Docente e investigador de la Universidad de Manizales (Colombia). email: miguelg@umanizales.edu.co

${ }^{3}$ Estudiante del doctorado Formación en Diversidad de la Universidad de Manizales, Magister en Educación de la Universidad de Caldas, docente de la institución educativa Instituto Kennedy de Pereira. e-mail: awchima@ hotmail.com Rev. Eletrônica Mestr. Educ. Ambient. Rio Grande, v. 37, n. 1, p. 09-26, jan/abr. 2020. 


\section{Muros e educação, duas tristes desigualdades da educação em Pereira, Colômbia}

Resumo: Este artigo de reflexão, oriundo da pesquisa avançada para a tese de doutorado (20162020), intitulado Espaços Confinados. Paredes físicas e simbólicas na cidade de Pereira, Colômbia: uma questão sobre educação, parte de uma discussão sobre a ideologia da segurança, como uma perspectiva classista e autoritária que ignora os direitos da grande maioria da população, sob o pretexto de um agressor externo. Entre os direitos violados por essa ideologia, está a educação e levanta muros na escola para proteger os estudantes de um diálogo direto com o mundo. Diante desse cenário de espaços confinados, e a título de conclusão, propõe-se, em primeiro lugar, a supressão, a derrubada dos muros físicos existentes para se abrir à comunidade, para se opor ao muro de realidades; em segundo lugar, criar uma pedagogia crítica que facilite um encontro dialógico entre os atores da comunidade educacional, os saberes e práticas reunidos para combater o pensamento em favor dos muros.

Palavras-chave: Muros da educação, ideologia da segurança, segregação espacial, educação confinada, pensamento de fronteira.

\section{Walls and education, two sad inequations of education in Pereira; Colombia}

Abstract: This reflection article, coming from the advanced research for the doctoral thesis (20162020), entitled, confined spaces. Physical and symbolic walls in the city of Pereira, Colombia: a question about education, starts from a discussion about the ideology of security, as a class and authoritarian perspective that ignores the rights of the vast majority of the population, under the pretext of an external aggressor. Among the rights violated by that ideology is education, and builds walls in the school to protect children from a direct dialogue with the world. Faced with this scenario of confined spaces, and by way of conclusion, it is proposed, in the first instance, the suppression, collapse of the existing physical walls to open up to the community, to oppose the walling of realities, secondly, to create a critical pedagogy to generate a dialogical meeting between the actors of the educational community, the knowledge and practices that are brought together to counteract the thinking in favor of the walls.

Keywords: Walls in education, security ideology, spatial segregation, confined education, border thinking.

\section{Introducción}

Muros segregacionistas que excluyen, seleccionan y desalojan al hombre de sí, para además de estar arrojado a soportar la existencia, a buscar la libertad, lo sentencian a ser un desgraciado o desgarrado por la imposibilidad de saltarlos (GONZÁLEZ, 2009, p. 273).

Estamos amurallados, vivimos entre muros simbólicos y físicos, muchas de estas barreras, por no decir, casi todas, son segregacionistas, ponen un límite, una distinción. Incluso cuando se cierran ciudades por enfermedades - caso actual, Marzo de 2020, de varias ciudades chinas e Italianas -, son muros que, en apariencia protegen a unos, pero condenan a otros a padecer, a soportar las ignominias, el miedo en sí. Sabemos que los militares, muchas religiones y políticos radicales, de izquierda, derecha o centro, son enamorados de los muros, de ahí que a cada problema se inventan un muro, un escenario 
desgarrador, desesperanzador por más aliados que siga teniendo la idea del murallón o los llamados refugios de seguridad.

Nos estamos llenando de instituciones educativas con llamativos, finos y tecnificados muros, pero sin ideas para confrontar los problemas sociales, sin ciencias para adelantarse a los tiempos o, al menos, para que una enfermedad o una amenaza de la naturaleza no haga tantos estragos en la sociedad.

Cuando pensamos una sociedad desmurallada, implica una escuela sin muros, no sólo físicos sino simbólicos, no para ir en pos de sociedades seguras, armadas, vigiladas y controladas, sino para aproximarse a sujetos con pensamientos críticos y abiertos, emancipados que, sean cuales sean las condiciones sociales, jamás validen la existencia de muros para segregar.

Pereira es una ciudad radicalizada en relación con sus muros, con sus barreras construidas alrededor de las escuelas, colegios, universidades y otras instituciones de formación. En tal sentido:

¿Quién es o qué es ser? Es alguien que se plantea la raíz de los fenómenos, dice también ir por sus causas y no emplea términos medios. Para un sujeto radical, las medianías no son viables, se es blanco o negro, está conmigo o contra. Para las comunidades radicales el vaso está lleno o vacío, todo o nada, se siente o no se siente. Un radical puede ser intransigente, necio, terco, ortodoxo, dogmático y paradigmático. Es una persona capaz de llegar hasta las últimas consecuencias. Cueste lo que le cueste, no cede. Un radical cree que los equivocados son los demás; a él no lo entienden porque es un adelantado de su tiempo o porque los demás lo hacen invisible (GONZÁLEZ, 2018b, p. 12).

Si no desradicalizamos nuestras apuestas, no logramos encontrar nuestros errores ¿Será esa radicalidad del amurallarse una sordera de la educación en Pereira, Colombia? El caso es que todas las instituciones de educación superior de la ciudad de Pereira, Colombia cuentan con muros, con cercas que encierran las instalaciones y, a lo mejor, encierran el pensamiento.

En cualquier caso, se encuentra esa curiosa manera que tenemos los humanos de amurallarnos, de confinarnos para no encontrarnos con otros, para huir de los demás. Así:

Lejos de ser vestigios del pasado, los muros están presentes en el mundo de hoy. El siglo XXI inventa otro tipo de muros: las fronteras que se amurallan para hacer frente a nuevos miedos, como la inmigración, el terrorismo, la pobreza, la violencia urbana o el crimen organizado (NOVOSSELOFF; NEISSE, 2011, p. 25). 
Es por ello que identificar las condiciones bajo las cuales se han construido muros físicos y simbólicos en las Instituciones Educativas ${ }^{4}$ de la ciudad de Pereira (Colombia) y su influencia en la incorporación de la diversidad en el territorio, no es una pregunta menor.

En Pereira, las instituciones educativas públicas han adoptado una estética de muros, levantando paredes y cercas, adoptando sistemas de seguridad y control y levantando rejas con las que limitan las relaciones con el entorno y con los habitantes de los contextos donde se ubican y desarrollan su propósito educativo.

Este trabajo se origina en la necesidad de comprender el fenómeno de los muros que se levantan en las relaciones entre las personas y que limitan sus posibilidades de una interacción libre y espontánea con su entorno y consigo mismas. A los muros físicos les anteceden otros muros "invisibles" que se elevan entre las personas y condicionan sus relaciones. Muros ideológicos, políticos y religiosos construidos con elementos culturales que afectan la calidad y el flujo de las intersubjetividades (CALDEIRA, 2007).

Como antecedentes investigativos, por lo tanto, se tuvieron en cuenta estudios asociados a muros físicos, muros simbólicos, seguridad, seguridad humana, educación en ciudad, seguridad humana desde abajo, perspectiva de derechos, derecho a la educación.

\section{Los muros y la ideología de la seguridad}

En la literatura encontrada, se hace referencia al concepto muro, que se toma como "la capacidad de interactuar con el espacio a través de funciones arquitectónicas variadas" (MARTINS, 2015, p. 7). El muro es comprendido por su función espacial y su interacción con el entorno desde una perspectiva arquitectónica. En todo caso, el muro parece algo natural, tan cotidiano y tan incrustado en nuestra cultura del espacio que no concebimos una casa sin muros, como sí la conciben otras culturas. Este es un concepto que se desarrolla en contextos económicos, sociales y culturales específicos, marcados por una cierta concepción del conflicto social, del ambiente natural y de las relaciones sociales con las que se organiza la economía y especialmente la empresa. Para muchos pueblos indígenas en el mundo, las casas con muros son inconcebibles y mucho menos los muros entre territorios o en torno a las ciudades. El contexto histórico en el que los muros

\footnotetext{
${ }^{4}$ Las Instituciones Educativas que se toman en este trabajo son las de educación básica y las de educación superior, que para propósitos de este artículo se seguirán llamando en genérico IE; salvo en los casos especiales que deban ser nombras de forma específica.

Rev. Eletrônica Mestr. Educ. Ambient. Rio Grande, v. 37, n. 1, p. 09-26, jan/abr. 2020.

E-ISSN 1517-1256
} 
empiezan a delimitar el espacio es muy preciso y corresponde a formas económicas exactas, al desarrollo de la guerra y al afianzamiento de la propiedad.

En Arquitectura, hay una referencia histórica al surgimiento del muro en las viviendas y en las ciudades, y se investigan asuntos como las murallas en las ciudades y en los castillos, hasta las grandes murallas que dividen territorios inmensos. Y en este trayecto, el muro, la ciudad amurallada, el castillo, las almenas, las garitas, los tímpanos, los antepechos, las troneras, los baluartes, las poternas, la barbacana, el foso, las saeteras y toda la terminología usada para las murallas se remiten a estrategias de guerra. El muro tiene, pues, un origen guerrero que lo marca como un artefacto del rechazo a los enemigos, que suelen ser los extranjeros, los bárbaros, los otros.

\title{
La simbología del muro
}

\begin{abstract}
¿Por qué empieza de pronto este desconcierto y confusión? (¿Qué graves se han vuelto los rostros!) ¿Por qué calles y plazas aprisa se vacían y todos vuelven a casa compungidos? Porque se hizo de noche y los bárbaros no llegaron. Algunos han venido de las fronteras y han contado que los bárbaros no existen. ¿Y qué va a ser de nosotros ahora sin bárbaros? Esta gente, al fin y al cabo, era una solución (CAVAFIS, 1904).
\end{abstract}

Los muros suponen memorias que alguien guarda en secreto, porque los muros permiten el secreto. Alguien dice: "si las paredes hablaran [...]" y se refiere a que hay algo que solo los muros que guardaron el secreto lo seguirán preservando como cofres o como tumbas. Y es que las tumbas, que se esconden entre muros, también son símbolo del secreto: "yo soy una tumba", se dice, para indicar que de mí no saldrá ninguna memoria sobre un hecho que se debe sepultar en el secreto de los muros. Así, pues, los muros guardan memorias de los constructores, memorias de los creadores que incubaron la idea de levantarlos, memorias de los artistas que los usan como lienzos o como murales, memorias de amoríos bajo su sombra, memorias de las violencias en sus criptas.Son memorias silenciadas por el muro como un arca que será abierta algún día y que dejará escapar, como pájaros de la noche, todos los secretos de los fantasmas o de los tesoros que el muro ha protegido.

El muro es esa estructura que se edifica para que los que están afuera no entren y los que están adentro no salgan. La opción defensiva y la solución política consisten precisamente en esa función aislante del muro (VÁSQUEZ; MARTÍN, 2006). Los muros, 
entonces, como dispositivos de división del espacio, representan fronteras o defensas contra las amenazas externas. Pero también cercan las cárceles, impiden la salida, privan de la libertad.

Los muros excluyen, segregan como nos indica el siguiente autor:

Las personas no debemos seguir cayendo en las alternativas de las alternativas. No seguirle apostando a la discriminación racional, a la discriminación social, saber que los seres humanos estamos hechos de nuestro pasado y que no podemos escapar de nuestra historia. Toda discriminación es un muro simbólico, un muro abstracto con efectos prácticos (GONZÁLEZ, 2018c, p. 105).

Al respecto, Vásquez y Martín (2006, p. 184) dicen que "El hombre se refugió tras paredes, empalizadas o murallas desde los orígenes de la civilización. Durante milenios, este modelo fue el único eficaz para la seguridad". De tal suerte que los muros, entendidos como fortalezas, han sido utilizados para defenderse de los agresores. Solo que los agresores suelen ser los Otros, los desconocidos, los bárbaros, los salvajes, los árabes, los comunistas, los chinos, los indios, los pobres y marginados o los extraterrestres. Todo lo que no somos "nosotros" es peligroso y es preciso levantar una muralla para defendernos de los agresores que quieren traernos su otredad. Debemos defendernos de lo desconocido o de los que hablan una lengua extraña (bárbaros significa, en griego, tartamudos, que son aquellos a quienes no se les puede entender lo que dicen porque hablan una lengua distinta a la propia). En este sentido, la función aislante del muro se relaciona con la seguridad de quienes necesitan protegerse de algo que puede agredirlos.

\section{La ideología de la seguridad}

Una vez fuimos tan pocos que nos daba miedo salir a explorar; hoy somos tantos que nos da miedo salir a caminar (GONZÁLEZ, 2018a, p. 4).

Nos han vendido miedos de todo orden, nunca hemos estado liberados de los mismos, estamos vinculados a muchos miedos, de ahí que, si antes temíamos salir a explorar, hoy nos da temor salir a caminar; una ideología que nos han vendido los poderes con sus lenguajes, nos meten el miedo y luego nos venden los esquemas de seguridad.

La seguridad tiene dos significados en la actualidad, y ambos tienen un profundo sentido de clase. El primero se refiere a la protección contra los agresores, puesto que se considera que las ciudades se han vuelto inseguras porque en ellas hay agresores, bandas 
criminales, que atentan contra la vida y la integridad de los ciudadanos. El segundo se refiere a la industria de la seguridad que pagan los ciudadanos para ser protegidos de los agresores externos.

En estos dos significados se encierran algunos sentidos autoritarios y clasistas que es preciso descubrir. En primer lugar, se habla de la defensa de los ciudadanos, como si los agresores no fueran ciudadanos. Pareciera, entonces, que como en la antigua Grecia (HABERMAS, 1994), se consideran ciudadanos los propietarios, a los cuales se les trata de defender la propiedad y la vida ${ }^{5}$ de aquellos que no tienen propiedad, de los desposeídos, que no se consideran ciudadanos y, por consiguiente, no tienen derechos.

Una idea autoritaria que recorre muchas ciudades del mundo contemporáneo se manifiesta en el afán del dominio y disciplinamiento social, mediante el control del espacio físico y del tiempo de la gente. En Medellín hay múltiples expresiones de este tipo de controles: por parte de actores legales se realizan prácticas como el encerramiento de centros habitacionales y comerciales, entidades públicas y espacios públicos; y aún existen barrios donde los actores ilegales ejercen una vigilancia poblacional, y donde incluso para transitar por las calles se requiere su autorización o acatar sus órdenes (ANGARITA CAÑAS, 2017).

De esta manera, la inseguridad, causada por "bandas criminales", se considera un mal del que es preciso protegerse y para ello, se ha creado toda una industria de la seguridad. De hecho, Edgardo Frigo, un experto en seguridad describe el sector económico de la seguridad en los siguientes términos:

Aunque macroscópicamente la seguridad Privada puede ser vista como un solo negocio, en realidad contiene múltiples segmentos y nichos, muchos de los cuales (pese a su valor económico) son "invisibles" para personas ajenas al sector. Cada uno de estos segmentos tiene una dinámica propia, con fuertes variaciones locales y regionales, y requiere un expertise específico para su abordaje [...] A nivel local y latinoamericano casi todos estos sectores se encuentran en fuerte crecimiento, frecuentemente mayor al 10\% anual acumulativo (FRIGO, 2017).

Como se puede observar, esta es toda una industria que se promueve como producción de bienes y servicios para garantizarle el derecho a la seguridad de los ciudadanos. Para ello, se ha abierto paso en la legalidad, como prestadora de servicios privados que manejan asuntos tan espinosos como la producción y distribución de armamentos, las agencias de seguridad y vigilancia (con empleados armados), protección

\footnotetext{
${ }^{5}$ Conviene saber que, en la constitución de 1886, los derechos que protegía esa constitución eran la propiedad privada, la vida y la libertad, y algunos políticos que atravesaron la primera mitad del siglo XX, como Laureano Gómez Castro, estaban convencidos de que esos derechos se concentraban en los propietarios.
}

Rev. Eletrônica Mestr. Educ. Ambient. Rio Grande, v. 37, n. 1, p. 09-26, jan/abr. 2020.

E-ISSN 1517-1256 
de VIP y guardaespaldas. Esto significa que el monopolio de la fuerza, en la práctica, no es del Estado, de modo que se forma una especie de ejército paramilitar legal para proteger la vida y la seguridad de los propietarios.

Por supuesto, según el artículo 216, las consecuencias políticas de esta promisoria industria se hacen sentir en la política con propuestas como la de la "Seguridad Democrática", que adopta un modelo de Estado Comunitario, en el que la seguridad corre por cuenta de cada grupo. Esta opción privada de seguridad, como es de imaginar, riñe con los principios del Estado moderno que le atribuyen el monopolio de la fuerza al Estado y, de ninguna manera a manos privadas (CP, 1991).

\section{La seguridad humana}

En el documento preparatorio de la declaración de la ONU sobre seguridad humana, en la comisión creada para el tema, Sadako Ogata y Amartya Sen definen el término de la siguiente manera:

[la seguridad humana es] la protección de la esencia vital de todas las vidas humanas de forma que se realcen las libertades humanas y la realización de los seres humanos. La seguridad humana significa proteger las libertades fundamentales, libertades que son la esencia de la vida. Significa proteger a las personas de amenazas y situaciones graves y generalizadas. Significa utilizar procesos que se basan en las capacidades y las aspiraciones de las personas. Significa crear sistemas políticos, sociales, ambientales, económicos, militares y culturales que, juntos, proporcionen a las personas los elementos básicos de medios de vida para la supervivencia, y dignidad (OGATA; SEN, 2003).

Según la ONU, la seguridad humana se refiere a siete ámbitos que son: seguridad económica, alimentaria, de la salud, del medio ambiente, personal, comunitaria y política. En este contexto, es claro que la inseguridad tiene causas más profundas que la simple probabilidad de una agresión física propinada por agentes sociales proclives a la delincuencia.

\section{La seguridad humana desde abajo y los derechos de la gente}

Hasta aquí, la seguridad humana como derecho de todos los ciudadanos, relativa a una serie de aspectos de las necesidades humanas, es un reconocimiento de las Naciones Unidas para todos los habitantes humanos del planeta, pero el significado vivo de este 
derecho a estar seguros respecto a la alimentación, al trabajo, a los servicios de salud, a albergarse en una vivienda digna, entre otros derechos, ese significado solo puede provenir de la gente en los contextos locales. Por eso:

El Observatorio de Seguridad Humana de Medellín retomó el enfoque de seguridad humana propuesto por la comisión del Programa de las Naciones Unidas para el Desarrollo (PNUD), encabezada por el profesor Amartya Sen (1994), y lo resignificó según las condiciones específicas de los sectores más vulnerados de la ciudad; de este modo, lo denominó Seguridad Humana Desde Abajo. Además, de las siete dimensiones iniciales del PNUD incluyó la seguridad para las mujeres (OSHM, 2010; ANGARITA CAÑAS, 2017).

La seguridad humana desde abajo completa la perspectiva de la ONU con el derecho a la seguridad de las mujeres y, además, le da significado en los barrios populares de Medellín. Y, en esta forma, la seguridad como concepto que da origen a los muros y a toda la parafernalia de la defensa de la propiedad y de la vida de los probables agresores "externos" que da origen a toda la ideología de la seguridad y también a la industria de la seguridad que alimenta el miedo como mecanismo de mercadeo.

\section{La perspectiva de derechos y las perspectivas o estructuras de la acogida}

La perspectiva de derechos surgió inmediatamente después de la segunda guerra mundial, con la Declaración Universal de los Derechos Humanos (ONU, 1948) expedida por la Asamblea General de las Naciones Unidas, en respuesta al exterminio del pueblo judío a manos del Fuhrer. Se trató de un acto imperialista de unos líderes desadaptados que consideraron a los judíos como una raza humana que no tenía derecho a existir sobre la faz de la tierra. Y se dedicaron sistemáticamente a exterminarla. Independientemente de otros motivos que hubieran tenido los nazis y los fascistas para arremeter contra el pueblo judío, el discurso de la pureza de la raza y de la superioridad de la raza aria (que Italia no tiene), se trataba del principio de negación del otro como justificación de una guerra contra el mundo.

No es que la gestación de los Derechos Humanos haya permitido implementarse en todas las naciones al unísono, en distintos lugares se han creados muros físicos y simbólicos para burlarse de la disposición, no es sino mirar el informe anual sobre Derechos Humanos para sorprendernos de lo que suele ocurrir, incluso, en países que dicen ser defensores de los mencionados derechos; sobre este déficit en la perspectiva de derechos ha hecho que algunos eventos, como el Foro Social Mundial temático en 2003 en Rev. Eletrônica Mestr. Educ. Ambient. Rio Grande, v. 37, n. 1, p. 09-26, jan/abr. 2020. 
Cartagena, se pronunciaran sobre la perspectiva de derechos como la posición progresista de defensa de los pueblos del mundo.

Posteriormente, en el año 2007, se llevó a cabo la discusión sobre políticas educativas en el marco del Proyecto Regional de Educación para América Latina y el Caribe (EPT/PRELAC) y se declaró que la educación es un derecho humano fundamental. Allí se plantea la necesidad apremiante de implementar políticas para asegurar una educación de calidad para todos, según un enfoque de derechos, reconociendo que, si bien se han adelantado en la región ingentes esfuerzos por brindar una mayor cobertura educativa de calidad, aún persisten problemas que afectan, de manera especial, a las personas y a los colectivos más vulnerables (UNESCO, 2007). En este sentido, se recalca la necesidad de garantizar una educación que permita el pleno ejercicio de los derechos humanos, en forma gratuita, sin discriminación y durante toda la vida.

Otro evento internacional crucial en la construcción del concepto de educación inclusiva, sus políticas y prácticas, fue la $48^{\text {a }}$ reunión de la Conferencia Internacional de Educación - CIE -, con el tema: La Educación inclusiva: el camino hacia el futuro, organizada por la Oficina Internacional de la Educación - OIE - de la UNESCO, celebrada en Ginebra en 2008. En razón de ello, uno de los aspectos más relevantes de este encuentro internacional tiene que ver con la definición del concepto inclusión, según la cual:

[...] puede ser concebida como un proceso que permite abordar y responder a la diversidad de las necesidades de todos los educandos a través de una mayor participación en el aprendizaje, las actividades culturales y comunitarias y reducir la exclusión dentro y fuera del sistema educativo (UNESCO, 2008, p. 8).

En suma, la perspectiva de derechos que incluye el derecho a la educación considera igualmente el derecho a no ser excluido por ninguna razón ideológica, cultural, política o económica.

\section{Las estructuras de acogida}

La perspectiva de derechos siempre será insuficiente respecto a las relaciones humanas porque el derecho se elabora siempre frente a la transgresión. El derecho a la vida no tendría sentido si no es porque en el mundo se asesinan muchísimas personas diariamente. El derecho a la educación no tendría sentido si no es porque los índices de ignorancia y de déficit educativo en el mundo son aplastantes. Entonces, la perspectiva de 
derechos cobra sentido como herramienta de lucha por obtener lo que falta. Pero eso que falta parece ser un elemento estructural de un mundo basado en una perspectiva de mercado. Los presupuestos mundiales para la guerra y para el desarrollo de asuntos nucleares y de la carrera espacial cubrirían, según muchos analistas, el déficit en educación y en alimentación en el mundo. Una buena posibilidad de cubrir las necesidades educativas de la sociedad, más allá de la perspectiva de derechos, abriendo de paso la escuela a nuevos saberes, a nuevas pedagogías, es que la institución escolar se convierta en una estructura de acogida (DUCH, 2002).

Es curioso, pero La Constitución Política (CP, 1991), emerge como estructura de acogida que no acoge, declara, en el artículo primero que corresponde a los principios fundamentales, que Colombia se funda en "el respeto de la dignidad humana, en el trabajo y la solidaridad de las personas que la integran y en la prevalencia del interés general" (CP, 1991), según el artículo 1. Ahora bien, en derecho, la Constitución debe ser exigible para que sea principio de la Ley, pero ¿cómo puede exigirse la solidaridad? ¿Cómo alguien puede reclamarle al Estado que se le tutele el derecho a que los demás sean solidarios con él o con ella? En tal sentido, si tornamos las instituciones de educación básica, secundaria y universitaria en estructuras de acogida, le estamos dando una lección a los poderes económicos, políticos y jurídicos. ¿Sí la educación es una estructura de acogida, cómo se comprenden sus muros físicos? Esto sin hablar de los muros simbólicos que abordaremos en otra narrativa.

Cuando Lluís Duch se refiere a las estructuras de acogida como fundamento de la sociedad humana, habla de estas estructuras en estos términos:

La expresión "estructuras de acogida" sólo tiene un alcance pedagógico, descriptivo y narrativo. Se trata de algo que, en todas las culturas humanas sin excepción, ha sido fundamental e irrenunciable para que la vida humana continuase sobre el planeta. La "acogida" es una estructura en el sentido que el ser humano, necesariamente, para alcanzar la estatura humana, ha de ser acogido. Se trata de algo que es coextensivo a la presencia del hombre en el mundo: ha habido, hay seres, esperemos que habrá seres humanos porque ha habido; que hay, habrá infantes (seres que aún no hablan); que su venida a este mundo ha sido, es, será posible porque han sido, son, serán acogidos (DUCH, 2008).

En ese sentido al que se refiere Duch, el derecho se puede comprender en el campo de la querella que se basa en el reclamo de los derechos, que son facturas que pueden ser reclamadas a otro ante el Estado que debe tutelar su efectividad. Desde Duch se testimonian las siguientes estructuras de acogida, la familia, la ciudad y la religión, uno 
como persona se siente acogido en la familia por el vínculo filial, en la ciudad porque es un lugar donde todo es posible, en términos de recepción y las religiones que en sus posturas saben recibir al otro, lo acogen para lo que ellas denominan transformación de vida. De ahí que la acogida se refiere a un principio ético contrario al derecho que se refiere a lo que Emmanuel Lévinas remite al des-interés:

Este inter-és debíamos convertirlo en des-inter-és, es decir, debíamos de ponernos en el lugar del otro sin esperar nada a cambio. Debíamos, por consiguiente, surgir del ego cartesiano y ver más allá de nosotros mismos; aceptar que somos, tal y como señalaba Aristóteles en su Política, animales cívicos; aceptar que a mi lado se encuentra el Otro, gracias al cual soy yo quien soy (GIL, 2006).

Ningún muro es una estructura de acogida, tal vez, la Muralla China, hoy sea una estructura de acogida para turistas, pero en sus inicios fue para segregar, para separar, para indicarle a algunos que si la franquean nada bueno les va a ocurrir. Lo cierto es que, si la muralla segrega, a su alrededor se gestan estructuras de soporte, organizaciones de acogida para las personas que desean transitar o comunicarse con alguien que se encuentra en la otra línea que divide el muro. Es usual que un poderoso construya una verja para separarse de la plebe, de aquello que le amenaza o no le gusta. De ahí que el muro entre México y USA lo ha construido el país adinerado, pero en sus alrededores, más usual del lado de los pobres, existen cantidad de organizaciones que hacen de estructura de acogida para los migrantes en su atención médica, psicológica, económica, educativa o religiosa, se convierten en una familia de paso, en un lugar de recogida religiosa. En las estructuras de acogida hay un interés por el otro, el alter llega para integrarse no para penalizarse.

En efecto, el inter-es pertenece al campo del derecho, de la querella, de la exigibilidad de la factura que significan los derechos. En cambio, el des-inter-és es solidaridad, ética del cuidado (GILLIGAN, 2013), la acogida, el amor. Y la sociedad que vincula no se basa en la exigibilidad del derecho, sino en la gratuidad de la solidaridad, de la acogida. El derecho es necesario porque se suelen ignorar los derechos gracias a la prevalencia de los inter-eses, y ante la crueldad y la expoliación del otro, es preciso esgrimir los derechos para evitar el daño. Pero el vínculo que permite la vida solo es posible sobre la acogida.

Un acercamiento de la educación, como derecho fundamental, es un primer paso que se ha dado, ahora nos corresponde convertirnos en estructuras de acogida, en lugares de llegada donde estudiantes, profesores y demás integrantes se sientan acogidos ¿Una 
institución amurallada, qué tipo de acogida nos ofrece? Todo lo que pongamos entre muros va siendo agresivo y no se traduce en estructura de acogida sino de segregación.

\section{La educación en la perspectiva de derechos}

La fortificación de las escuelas modernas tiene ese signo de impedir el intercambio entre el adentro y el afuera. Se parte del principio de que el mundo es peligroso y agresivo y que los niños deben ser protegidos del contacto con ese mundo, porque en él pueden ser maltratados, violados, agredidos, secuestrados, abusados, y la escuela levanta un muro para poder responderles a los papás cuando llegan a reclamar a sus hijos. ¿Justifica ello plagar la escuela de verjas? ¿Justifica ello que las instituciones de educación se encierren en sus murallas y se cierren para la comunidad? En tales condiciones de confinamiento, la mediación única del conocimiento del mundo en la escuela es el profesor que les enseña a los niños consignados bajo su cargo.

En efecto, en la actualidad, el mundo reviste riesgos para los niños y las niñas porque el conjunto de la sociedad los ha generado. Según algunos entrevistados, en las ciudades del Eje Cafetero, hace 60 años, los niños iban a pie al colegio y no había los obstáculos que actualmente se presentan para que pudieran salir a la calle. Pero hoy, esa práctica sería temeraria porque las ciudades grandes se han hecho inseguras y sería insensato que las escuelas no tuvieran barreras para impedir que los abusadores entraran a las instalaciones de la escuela a hacer lo que saben hacer o que los pilluelos entraran a robarse algunos libros, aunque como dice (GONZÁLEZ, 2004) a un ladrón de libros habría que temerle menos que a los desfalcadores del presupuesto, que a la corruptela política que nos venden muros para seguir escondidos en sus murallas.

Entonces, en un contexto que no ofrece seguridad y una atmósfera tensa por la creciente amenaza de demandas, resulta comprensible que un padre de familia tema por el bienestar de su hijo y opte legítimamente por los muros de la escuela. Además, las Secretarías de Educación y las instituciones educativas, habitualmente se cuidan de seguir estrictos protocolos de seguridad con el propósito de evitar posibles demandas y, una de las soluciones es enrejar las instalaciones e incluso poner concertinas y cercas con descargas eléctricas. No obstante, ¿qué mensajes le enviamos a las sociedades del presente potencial? Entre muchos, uno de ellos, es construir muros, seguir segregando. Por eso, el encerrar no es una solución sino la radicalización de un problema mayor. Pero, entonces, hay que abrir las puertas de la cabeza de los profesores para que contribuyan a abrir las puertas de la Rev. Eletrônica Mestr. Educ. Ambient. Rio Grande, v. 37, n. 1, p. 09-26, jan/abr. 2020. E-ISSN 1517-1256 
cabeza de los alumnos que necesitan una guía y un estímulo para la libertad. Esto comporta para los profesores, el desafío de abrir mediaciones pedagógicas a fin de que los muros de la escuela cumplan en efecto una función protectora de los estudiantes y no se constituyan sólo en dispositivos que les confinan y marginan de su entorno.

Nos resultan claves aquí las palabras de Ospina:

Causa perplejidad que se nos encierre en lóbregos recintos para iniciarnos en el conocimiento de la naturaleza, que debamos escuchar por horas y por meses un saber aburrido y fósil mientras afuera discurre el milagro del mundo. Sin duda es extraño estudiar botánica lejos de los bosques, estudiar reinos de la naturaleza en rígidos salones humanos. Es triste que antes que ayudarnos a ser individuos se nos obligue a ser sumisos rebaños (OSPINA, 2013, p. 185).

\section{El derecho a la educación humana desde abajo}

La libertad es la esclavitud. La ignorancia es la fuerza. La guerra es la paz (ORWELL, 2019, p. 8).

Nos hablan de muchos derechos en abstracto, como para calmar nuestros reclamos, de hecho, hay que cuidarnos de los eufemismos como nos advierte Orwell, en su gran novela de 1949, "la guerra es la paz", donde el Ministerio de la verdad se encarga de las bellas artes, las noticias, los espectáculos y la educación ¿Sí existe un Ministerio de la Verdad, quién se encarga de las mentiras? La educación siempre ha estado en el centro de las distintas apuestas políticas del siglo XX y XXI, pero, en muchos casos, se apoyan en Orwell, "la ignorancia es la fuerza" y eso es lo que parece con esto de las instituciones educativas amuralladas en Pereira.

Ahora, no todo está perdido, también, en medio de los muros, algo se piensa, algo se moviliza, como ejemplo, tenemos el Observatorio de Seguridad Humana de Medellín, el cual completa la declaración de la ONU sobre seguridad humana y le da significado en la vida de las comunidades populares de la ciudad. Es posible igualmente pensar en una escuela que garantice el derecho a la educación humana desde abajo, es decir que parta de los alumnos y los maestros en un diálogo fértil. Este ejemplo es una ruta que las autoridades en educación de Pereira deben revisarla, significarla si queremos una ciudad distinta a lo que el neoliberalismo, el capitalismo salvaje nos ha vendido, personas esclavas trabajando, unas haciendo muros, otras cárceles, otros sistemas de vigilancia y muy pocas dedicadas a la alta ciencia, al cultivo de la humanidad. 


\section{Por una sociedad sin muros que haga posible una escuela sin muros, un breve viaje a las conclusiones}

Estamos en tiempos intoxicados, en sociedades agendadas, sociedades amuralladas, sociedades que sospechan de todo mundo, sociedades sin tiempo para pensarse y con tiempo para ser sometidas (GONZÁLEZ, 2015).

Pereira, ciudad central del Eje Cafetero, así como la mayoría de ciudades en Colombia, requiere pensar y actuar con prontitud para derrumbar los distintos muros que poseen las instituciones educativas que, vistas desde afuera, parecen pequeñas cárceles, con cámaras, muros, cercas, portales y vigilantes que están para controlar el acceso.

La escuela hay que entenderla inscrita en una sociedad. Su estructura, su arquitectura, el conocimiento que distribuye, la pedagogía que emplea, sus contradicciones y su complejidad provienen de la sociedad en la que se inscribe. De tal modo que una escuela sin muros, una escuela abierta al mundo, una escuela no autoritaria solo es posible en una sociedad capaz de abrirse al otro, que rompa las estructuras patriarcales y que derribe sus muros.

Nos han hecho creer que la sociedad es peligrosa, los peligrosos son los poderes que han generado desigualdades, iniquidades, segregaciones, humillaciones, de eso hay una larga lista en los poderes pereiranos, junto a un sistema político autoritario, corrupto, lo que da paso a una cultura en la que la vida, la libertad y la dignidad de las gentes valen menos que el capricho de cualquier poderoso ¿Estas inequidades justifican los amurallamientos? Para los poderes que los disponen, la respuesta es sí, para esta investigación, apoyada en los distintos diálogos, la respuesta es no.

Por tanto, se propone la escuela, la universidad, la educación en general de la ciudad de Pereira, como centros de resistencia frente a los poderes obnubilados, autoritarios, patriarcales que han dispuesto muros en todos los centros educativos de la ciudad, bajo curiosos sofismas que nada tienen que ver con la educación, la libertad, la emancipación y el pensar crítico.

Somos claros, esta propuesta propone derribar los muros físicos y simbólicos, los segundos devenidos de un pensar cansino, clasista, racista, excluyente y homogéneo que pueden albergar muchos profesores que están convencidos de la necesidad de construir muros. 
Al derribar los muros se llega a un diálogo genuino entre maestros y alumnos, entre padres e hijos, entre saberes y prácticas, entre ningunos, nadies y cualquieras. En tal sentido:

[...] la educación debe pensarse y centrarse en el ser humano, no en los contenidos, sino en todas las experiencias que de la persona deviene y sus lecturas de mundo; es decir, llenos de sentimientos, olvidos, pasiones e impulsos, acuñados, oprimidos, sin posibilidad de movimiento, de movilización, como sujetos liberados y no sujetados en las estructuras institucionales y familiares, una avenida de ida y vuelta, entre la enseñanza y el aprendizaje, pluralista y diverso (SALDARRIAGA, 2019, p. 49).

Muros y educación son una inecuación, frente, por ejemplo, a la crisis sanitaria del coronavirus ¿Cuántas instituciones de Pereira han entregado alternativas? Casi ninguna, unas pequeñas voces de la Universidad Tecnológica, los demás en silencio ¿No será que esos dinerales dedicados a construir y cuidar muros no nos dejan recursos para la ciencia? Por eso nuestros laboratorios son de segundo nivel, los existentes son para unos privilegiados.

Sigamos construyendo muros en las instituciones educativas en Pereira y veremos los pobres resultados científicos para abordar los problemas sanitarios que venimos visualizando con relación al coronavirus, esto por poner un ejemplo de último momento, pero que podemos revisarlo a lo largo de la historia para conmovernos.

Si Pereira, no da un salto político y educativo de desmurarse, es posible que para la próxima gran dificultad social no tenga claves científicas para resolverlas, pero si suficientes muros para confinar enfermos, locos, criminales en que deberán convertirse los líderes si no adoptan una ruta distinta a la de edificar muros físicos que dan paso a los muros simbólicos con todas las implicaciones que esto trae.

La emancipación de estas realidades adquiere sentido desde un movimiento consciente cual como propone Freire (FREIRE, 1969), donde la educación sea, en efecto, una práctica de la libertad. Esta será una libertad capaz de derribar los muros, de liberarse de los odios y de adelantarse, con suficiente trabajo científico, a las dificultades que devengan.

Urge la práctica de una educación de Pereira y de Colombia, es posible que en otros lugares del mundo también aplique, que nos enseñe a romper los muros, arañarlos, dejar de creer que el muro es la alternativa frente a la delincuencia, frente al diferente. El muro, las vallas no pueden seguir siendo un estilo de vida en la educación de Pereira, no podemos 
seguir teniendo universidades rodeadas por cercas, controles electrónicos, con bibliotecas cerradas los fines de semana para la comunidad a la cual se debe.

\section{Referencias}

ANGARITA CAÑAS, Pablo Emilio. Comunidades urbanas defienden sus derechos en contextos violentos e inseguros. In: ANGARITA CAÑAS, Pablo Emilio; VEGA, Jesica. Violencia, seguridad y derechos humanos. 1. ed. Ciudad Autónoma de Buenos Aires: CLACSO, 2017.

CALDEIRA, Teresa Pires do Río. Ciudad de muros. Barcelona: Gedisa. 2007

CAVAFIS, Constantinos Petros Fotiadis. Esperando a los barbaros. 1904.

CP. Constitución Política de Colombia. Bogotá: Asamblea Nacional Constituyente. 1991.

DUCH, Lluís. Antropología de la vida cotidiana: simbolismo y salud. Madrid: Trotta, 2002.

DUCH, Lluís. Del trayecto autobiográfico al proyecto antropológico. Entrevista con Lluís Duch realizada por Blanca Solares y Manuel Lavaniegos. In: DUCH, Lluís;

LAVANIEGOS, Manuel; CAPDEVILA, Marcela; SOLARES, Blanca. Antropología simbólica y corporeidad cotidiana. Cuernavaca: UNAM - CRIM, 2008.

FREIRE, Paulo. La educación como práctica de la libertad. México: Siglo XXI, 1969.

FRIGO, Edgardo. Cómo se compone la industria de la Seguridad Privada. 2017. Foro de Seguridad. Disponível em: http://www.forodeseguridad.com/artic/admin/5120.htm. Acesso em: 15 ago. 2019.

GIL, Paula. Teoría ética de Lévinas. Cuaderno de materiales. 2006. Disponível em: http://www.filosofia.net/materiales/num/num22/levinas.htm. Acesso em: 15 ago. 2019.

GILLIGAN, Carol. La ética del cuidado. Barcelona: Fundació Víctor Grífols i Lucas, 2013.

GONZÁLEZ, Miguel Alberto González. Analectas de la caverna. Pereira: Papiro, 2004.

GONZÁLEZ, Miguel Alberto González. Horizontes humanos: límites y paisajes.

Manizales: Universidad de Manizales, 2009.

GONZÁLEZ, Miguel Alberto González. Tiempos intoxicados en sociedades agendadas. Sospechar un poco del tiempo educativo. Bogotá: Desde Abajo, 2015.

GONZÁLEZ, Miguel Alberto González; MONTAÑO, Jorge Luis Muñoz. Instantáneas en torno a la pedagogía y el desarrollo humano. In: VALDÉZ, Julián Enrique Páez (coord.) 
Comunicación, educación y cutlura: movilidades y perspectivas. Pereira: Universidad Católica de Pereira, 2018a.

GONZÁLEZ, Miguel Alberto González. Iras sordas y ciegas de los radicales al pensar las diversidades e inclusiones. In: GONZÁLEZ, Miguel Alberto González (compilador).

Diversidades e inclusiones. Pereira: Universidad Católica de Pereira, 2018 b.

GONZÁLEZ, Miguel Alberto González. Las vergüenzas de incluir-excluir en la educación, preguntas en diverser y diversar. In: KAPLAN, Carina Viviana. Emociones, sentimiento y afectos: las marcas subjetivas de la educación. Buenos Aires: Miño Dávila, 2018c.

HABERMAS, Jürgen. Historia y crítica de la opinión pública: la transformación estructural de la vida pública. México: Gustavo Gili, 1994.

MARTINS, Joana María. EI muro como referencia arquitectónica. Madrid: Universidad Tecnológica de Madrid, 2015. Disponível em: http://oa.upm.es/40518/. Acesso em: 15 ago. 2019.

NOVOSSELOFF, Alexandra; NEISSE, Frank. Muros entre los hombres. Bogotá, D.C.: Sello Editorial Alma Mater, 2011.

OGATA, Sadako; SEN, Amartya. La seguridad humana ahora: proteger y habilitar a la gente. New York: Comisión sobre Seguridad Humana, 2003.

ONU. Declaración Universal de los Derechos Humanos de 1948. Disponível em: http://www.un.org/es/universal-declaration-human-rights/. Acesso em: 15 ago. 2019.

ORWELL, George. El gran Hermano 1984. Caracas: Lucemar, 2019.

OSPINA, William. La escuela de la noche. Bogotá: Mondadori, 2013.

SALDARRIAGA, Natalia. Reflexiones autobiográficas desde el tiempo de una mujer docente. REMEA - Revista Eletrônica do Mestrado em Educação Ambiental, v. 36, n. 1, p. 43-62, 2019. Disponível em: https://periodicos.furg.br/remea/article/view/8936/5771. Acesso em: 15 ago. 2019.

UNESCO. Organización de las Naciones Unidas para la Educación, la Ciencia y la Cultura. Educación de calidad para todos: un asunto de derechos humanos. Buenos Aires: UNESCO, 2007.

UNESCO. Organización de las Naciones Unidas para la Educación, la Ciencia y la Cultura. La educación inclusiva: el camino hacia el futuro. Ginebra: UNESCO, 2008.

VÁSQUEZ, Sigfrido; MARTÍN, Virginia. La seguridad tras el muro: ¿una opción defensiva o una solución política? HAOL, v. 11, p. 183-194, otoño, 2006. Disponível em: https://dialnet.unirioja.es/descarga/articulo/2479570.pdf. Acesso em: 15 ago. 2019. 